\title{
A study of grip endurance and strengh in different elbow positions
}

\author{
A. J. Shyam Kumar · V. Parmar · S. Ahmed · \\ S. Kar - W. M. Harper
}

Received: 15 February 2008/ Accepted: 7 June 2008/Published online: 2 July 2008

(C) Springer-Verlag 2008

\begin{abstract}
Background The aim of our study was twofold. The first was to investigate the optimum position of the elbow while measuring grip endurance. The second was to investigate the optimum position of the elbow while measuring peak grip strength. The American Society of Hand Therapists advocate estimation of grip strength with the elbow flexed at $90^{\circ}$ with the subject in the sitting position. As far as we are aware, there have been no reports in English literature regarding studies done to evaluate the position of the elbow while measuring grip endurance.

Materials and methods $\mathrm{A}$ total of 45 healthy adults (16 males, 29 females) participated in this study. A computerised handgrip analyser was used to measure the peak strength in the non-dominant hand, followed by measurement of the grip endurance. These measurements were conducted in $90^{\circ}$ of flexion and full extension of the elbow for each participant.

Results Mean endurance in flexion was 71.0 N (SD 22.9) and in extension was 68.7 N (SD 27.4). Mean peak grip strength in flexion was $262.8 \mathrm{~N}$ (SD 73.1) and in extension was $264.1 \mathrm{~N}$ (SD 82.0). $T$ test analysis showed no statistical significance for elbow positions for grip endurance $(P=0.67)$ and peak gip strength $(P=0.93)$.
\end{abstract}

A. J. Shyam Kumar · V. Parmar · S. Ahmed · S. Kar .

W. M. Harper

Department of Orthopaedics, Clinical Sciences Building, University Hospitals Leicester NHS Trust, Glenfield Hospital,

Groby Road, Leicester LE3 9QP, UK

A. J. Shyam Kumar ( $₫)$

Flat-23, Rhos Gwyn, 493 Abergele road,

Colwyn bay LL29 9AE, UK

e-mail: ajshyamkumar@hotmail.co.uk
Conclusion Practical implications from this study are that grip endurance training can be undertaken with the elbow in $90^{\circ}$ of flexion or full extension.

Keywords Hand strength - Physical endurance · Muscle $\cdot$ Skeletal $\cdot$ Racquet Sports · Elbow

\section{Introduction}

Grip strength is one of the many components tested while evaluating hand function. It also provides an objective index of the functional integrity of the upper extremity $[1,2]$. Measurement of grip strength is also an important component of hand rehabilitation as it is a measure of the effectiveness of therapy [3]. Estimation of hand grip strength has also been used as a bedside tool to predict the development of postoperative complications in fracture neck of femur [4]. It has also been used for the same effect in vascular surgery [5]. The American Society of Hand Therapists advocate estimation of grip strength with the elbow flexed at $90^{\circ}$ with the subject in the sitting position [6]. As far as we are aware, there have been no reports in English literature regarding studies done to evaluate the position of the elbow while measuring grip endurance. The aim of our study was twofold. The first was to investigate the optimum position of the elbow while measuring grip endurance. The second was to investigate the optimum position of the elbow while measuring peak grip strength.

\section{Materials and methods}

The study was done in 2004, approved by the University department of Orthopaedics, Leicester and it was decided 
that formal ethical committee approval was not required as it was a non-invasive study and the subjects in the study were not patients. There were no patients in this study and all colleagues who participated gave informed consent for the study. Our sample consisted of 45 healthy adult volunteers (16 males, 29 females) comprising of nurses, paramedical staff and doctors from the Trauma and Orthopaedic department at Leicester Royal Infirmary, Leicester, United Kingdom. None of the volunteers had any abnormalities or any painful conditions of the upper limb. The mean age of the participants was 29 (range 19-58).

\section{Instruments}

The measurement was done with a digital grip analyser (MIE medical research limited, Leeds, United Kingdom) made from a special lightweight but stiff aerospace alloy which was adjustable to accommodate all hand sizes. This is connected to a digital display unit which was connected to a multianalyser PC for detailed analysis and real time biofeedback. The analysis was done with the WIN CAS software (Copyright $^{(} 2002$ MIE Medical Research Ltd.).The accuracy of the system is $1 \mathrm{~N}$ throughout the whole physiological range.

\section{Procedure}

Informed consent was obtained and at first, the examiner explained to the subjects regarding the procedure followed by a demonstration. The non-dominant hand of the subjects was chosen. All the measurements were taken in the standing position. Initially the peak grip strength was measured with the elbow in the chosen alternating position $\left(90^{\circ}\right.$ of flexion or full extension) (i.e. according to the initial position of testing in the previous subject). If the initial position in the previous subject was in flexion, then the initial position in the next subject was chosen as extension. This value was recorded in the multianalyser and the ability of the subject to sustain a grip contraction at $80 \%$ of the peak value was assessed (target time of $15 \mathrm{~s}$ ) with real time biofeedback from the computer screen. The results were analysed by WINCAS software $\left(\right.$ Copyright ${ }^{(}$ 2002 MIE Medical Research Ltd.). An arbitrary time period of 2 min was given between the starting of each measurement.

\section{Results}

The results were analysed using Microsoft Excel ${ }^{\circledR}$ (Microsoft Corporation, USA). The mean grip endurance with the elbow in $90^{\circ}$ flexion was 71. Newtons (SD 22.9) and the mean grip endurance with the elbow in full extension was 68.7 N (SD 27.4). A 2 tailed ' $t$ ' test was done showing a $p$ value of 0.67 . The mean grip strength with the elbow in $90^{\circ}$ flexion was $262.8 \mathrm{~N}$ (SD 73.1). The mean grip strength with the elbow in full extension was $264.2 \mathrm{~N}$ (SD 82.0). A two tailed 't' test was performed showing a $P$ value of 0.93 (Table 1).

\section{Discussion}

Although previous studies have looked at the relationship between maximum grip strength and grip endurance [7], there are no reports in English literature looking at the effects of elbow position on grip endurance. Our study shows that there is no statistically significant difference between different positions of the elbow $\left(90^{\circ}\right.$ flexion and full extension) for peak grip endurance values.

Studies by various authors have provided conflicting evidence regarding the optimum position of the elbow while assessing grip strength. Kuzala et al. [8] in a study of 46 subjects concluded that the strongest grip strength was at $0^{\circ}$ of flexion. Su et al. [9] in a study of 160 subjects, reported similar findings. But their study also looked at the position of the shoulder and their highest measurement was obtained with the shoulder in $180^{\circ}$ of flexion. The above mentioned studies contradict the results of Mathiowetz et al. [10] who found that stronger grip strength measurements were obtained with the elbow in $90^{\circ}$ flexion. Higher grip strength in extension of the elbow was also reported by Balogun et al. [11] in a study involving 61 subjects. They also found that a greater strength was obtained when the subjects were standing compared to the sitting position. This was attributed to the increased temporal and spatial summation of the contracting muscles in the standing position apart from increased cortical and peripheral

Table 1 Summary of results

\begin{tabular}{llll}
\hline & $90^{\circ}$ of elbow flexion & Full elbow extension & $P$ value \\
\hline Mean hand grip endurance & $71.0(22.9)$ & $68.7(27.4)$ & 0.67 \\
Mean hand grip strength & $262.8(73.1)$ & $264.1(82.0)$ & 0.93 \\
\hline
\end{tabular}

SD values given in brackets 
arousing. In order to obtain maximal values, all our subjects were tested in the standing position with the shoulder and forearm in neutral positions. The wrist was positioned in extension depending upon the comfort of the patient but flexion at the wrist was avoided as a previous study has shown that there was no significant difference in the relationship between the amount of dorsiflexion and hand grip strength whereas flexion of the wrist was found to give lower hand grip strength [12].

The results of our study revealed that there was no statistically significant difference in the peak grip endurance and peak grip strength values with the elbow in full extension or in $90^{\circ}$ flexion.

Our study has particular relevance to injuries to the elbow where the patient needs to be immobilised in an above elbow plaster or in combined injuries of the elbow and hand where hand rehabilitation can be started early and full grip strength potential can be expected irrespective on the position of the elbow. It is also relevant in patients with multiple joint arthritis (e.g. Rheumatoid arthritis) with fixed deformities of the elbow where grip strength and endurance rehabilitation can be achieved irrespective of the elbow position. A decrease in grip strength with the elbow in extension than in flexion may also indicate lateral epicondylitis as this has been reported before [13].The practical implications of this study can also be utilised in racquet sports where grip endurance training may be achieved with the elbow fully extended or in $90^{\circ}$ flexion.

\section{References}

1. Myers CR, Golding LA, Sinning WE (1973) The Y' way to physical fitness, 1st edn. Rodale Press Inc, Emmaus, pp 49-50

2. Myers DB, Grennan DM, Palmer DG (1980) Hand grip function in patients with rheumatoid arthritis. Arch Phys Med Rehabil 61:369-372

3. Fraser C, Benten J (1983) A study of adult hand strength. Br J Occup Ther 10:296-299

4. Davies TCW, Jones MD, Shearer JR (1984) Hand grip-a simple test for morbidity after fracture of the neck of femur. J R Soc Med 77:833-836

5. Griffith CDM, Whyman M, Bassey EJ (1989) Delayed recovery of hand grip strength predicts postoperative morbidity following major vascular surgery. Br J Surg 76:704-705

6. Fess EE, Moran C (1981) Clinical assessment recommendations. American Society of Hand therapists Monograph, Indianapolis

7. Nwuga VC (1975) Grip strength and grip endurance in physical therapy students. Arch Phys Med Rehabil 56(7):297-300

8. Kuzala EA et al (1992) The relationship between elbow position and grip strength. Am J Occup Ther 46:509-512

9. Su C, Lin JH et al (1994) Grip strength in different positions of the elbow and shoulder. Arch Phys Med Rehabil 75:812-815

10. Mathiowetz V, Rennells C, Donahoe L (1985) Effect of elbow position on grip and key pinch strength. J Hand Surg 10A(5): 694-697

11. Balogun JA, Akomolafe CT, Amusa LO (1991) Grip strength: effects of testing posture and elbow position. Arch Phys Med Rehabil 72:280-283

12. Kraft GH, Detels PE (1972) Position of function of the wrist. Arch Phys Med Rehabil 53:272-275

13. Dorf ER, Chhabra AB, Golish SR, McGinty JL, Pannunzio ME (2007) Effect of elbow position on grip strength in the evaluation of lateral epicondylitis. J Hand Surg [Am] 32(6):882-886

Conflict of interest statement There is no conflict of interest. 